\title{
Homenaje al doctor José Félix Patiño Restrepo 15 de febrero de 1927 - 26 de febrero de 2020
}

\author{
Tribute to Dr. José Félix Patiño Restrepo \\ February 15, 1927 - February 26, 2020 \\ Homenagem ao doutor José Félix Patiño Restrepo \\ 15 de fevereiro de 1927 - 26 de fevereiro de 2020 \\ Diana Cárdenas ${ }^{1 *}$ \\ https://doi.org/10.35454/rncm.v3n1.012
}

"La medicina es una actividad intensamente moral"

José Félix Patiño Restrepo

La medicina en Colombia ha perdido uno de sus más importantes pilares y la nutrición clínica su principal precursor. El doctor José Félix Patiño Restrepo murió el 26 de febrero de 2020 a los 93 años en Bogotá.

Pensó y vivió la medicina como pocos médicos en Latinoamérica lo han hecho. A través de su obra y de sus enseñanzas demostró el amor y la pasión por el arte médico. Humanista por excelencia, supo impregnar en la práctica de la medicina el más alto sentido ético y altruista. Su amor por los libros lo llevó a tener la más importante colección de libros de medicina con 13.000 volúmenes, donde también se podían encontrar libros de filosofía, historia y ópera, entre otros. Recuerdo como con gran orgullo invitaba a sus residentes e internos a su casa a conocer su biblioteca. La mostraba como quien presenta su primer amor, lleno de ilusión, sencillez, sinceridad y agrado. Entrar allí significaba entrar al mundo infinito del conocimiento del cual se salía transformado, con un afán indescriptible de querer acercarse, de querer saber más. Esta visita se terminaba en el comedor donde tomábamos un refrigerio, acompañado de una grata conversación sobre libros, historia, la vida, y siempre escuchando la voz de María Callas, su musa, su amor eterno. Esto nos permitió conocer un ser humano generoso, culto, humanista. De esa primera visita a

\footnotetext{
Editora Revista de Nutrición Clínica y Metabolismo

*editor-rmnc@nutriclinicacolombia.org

dianacardenasbraz@gmail.com
}

su biblioteca guardo como un tesoro un casete de 90 minutos grabado con la voz del doctor Patiño ¿Qué es la Ópera?

Hoy su colección se encuentra reunida en la biblioteca central de la Universidad Nacional de Colombia, institución que siempre consideró su casa, y que será garante de mantener su unidad. Fue inaugurada el 15 de febrero de 2017 con el nombre «Biblioteca José Félix Patiño Restrepo».

Sus aportes brillan tanto en lo científico y académico como en lo social y político. Entre ellos se encuentra el desarrollo de la Nutrición Parenteral en el marco de la terapia nutricional en Colombia, la Clínica de Marly y el Hospital de la Samaritana fueron testigos de sus inícios en los años 70. Fue cofundador del hoy Hospital Universitario Fundación Santa Fe de Bogotá, donde instituyó, al comienzo de los 80 , uno de los primeros grupos de soporte nutricional interdisciplinario en Latinoamérica. Desde entonces allí se forman médicos, enfermeras, químicos farmacéuticos, nutricionistas y otros profesionales en terapia nutricional, que el doctor Patiño llama, con gran erudición, el cuarto advenimiento $^{(1)}$. Para el doctor Patiño Restrepo, la nutrición parenteral se posiciona después de la anestesia, los principios de asepsia y antisepsia y la aparición de los antibióticos como el cuarto advenimiento o uno de los grandes paradigmas en la medicina. Lo define como un "gran suceso, un acontecimiento en el devenir histórico de la medicina”. Es por esto que la Revista de Nutrición Clínica y Metabolismo inauguró su primer número con un editorial invitado titulado "El Cuarto Advenimiento". Allí, el doctor Patiño hace referencia y homenaje al doctor Stanley J. Dudrick como el pionero en la nutrición 
parenteral. Cosas del destino, el doctor Dudrick murió el pasado 18 de enero, y en este número de la revista también le rendimos homenaje. La nutrición clínica está de duelo no solo en Latinoamérica, sino en el mundo.

El doctor Patiño fue un gran visionario y siempre a la vanguardia de la tecnología. Entre otras, la información médica computarizada se hizo posible en Colombia gracias a un convenio firmado entre la Biblioteca Nacional de Medicina (EE.UU.) y el gobierno colombiano, y fomentado por el doctor Patiño. En el campo de la terapia nutricional, cuando el mundo intentaba salir del modelo de "hiperalimentación" con grandes aportes calóricos en la década del 90, él y su grupo publicaron en el World Journal of Surgery en 1999 los resultados de la alimentación hipocalórica en el paciente en estado crítico. Mostraron como una nutrición hipocalórica e hiperproteica en los primeros días de la fase flow de la respuesta adaptativa al estrés podría tener beneficios en la respuesta metabólica y probablemente en los $\operatorname{costos}^{(3)}$. Hoy otros investigadores están intentando confirmar lo que el doctor Patiño y su grupo mostraron 20 años atrás.

Su pasión por la historia y la epistemología venían a completar sus reflexiones académicas. En su libro Metabolismo, Nutrición y Shock, (cuyo prólogo fue escrito por el doctor Dudrick) en el capítulo sobre las bases biológicas de nutrición, define estas bases como la esencia misma del proceso vital. No se limita a definir las bases termodinámicas y genéticas de este proceso, sino que hace un extenso viaje por el tiempo y el espacio que inicia con la paleoquímica, para a través de la nutrición "explicar el origen de la vida misma, su permanencia y su desarrollo sobre la Tierra"(3).

Es por todo esto que no me sorprendió cuando durante mi primer año en la ciudad de París en 1998, me hizo el encargo de traducir del francés al español un texto sobre la decoración mural del gran anfiteatro de la escuela de medicina de la Universidad Paris Descartes. Hice mi tarea con gran esmero, la cual acompañé de una foto tomada durante la visita a la que sería poco tiempo después mi Universidad. Este mural pintado por Urbain Burgeois a finales del siglo XIX, muestra una asamblea en disposición neoclásica de los grandes médicos desde la antigüedad hasta el siglo XIX. Sin duda, podríamos darle a los doctores Patiño y Dudrick un espacio de honor en esta asamblea.

En este número de la Revista rendimos homenaje a dos grandes seres humanos que dieron todo por la medicina, sus pacientes y sus alumnos. La nutrición clínica esta huérfana. Su legado vivirá por siempre.

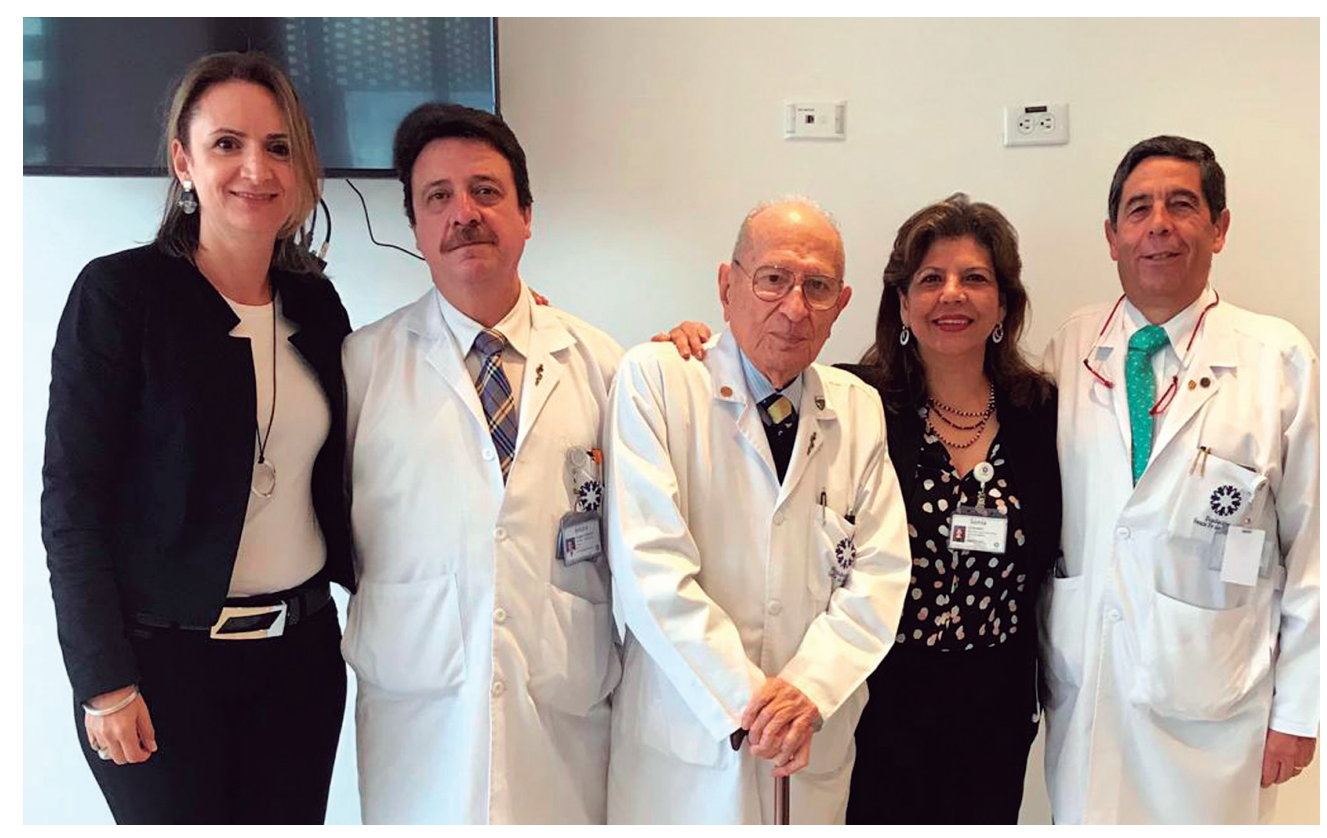

De izquierda a derecha: los doctores Diana Cárdenas, Arturo Vergara, José Félix Patiño Restrepo, Sonia Echeverri, Manuel Cadena. Foto tomada en la inauguración del 42 Curso internacional de Terapia Metabólica y Nutricional en el Hospital Universitario Fundación Santa Fe de Bogotá, abril 2019. 


\section{Referencias bibliográficas}

1. Patiño JF. El cuarto advenimiento. Rev. Nutr. Clin. Metab. 2018;1(1):20-25.

2. Patiño JF, de Pimiento SE, Vergara A, Savino P, Rodríguez M, Escallón J. Hypocaloric support in the critically ill. World J Surg. 1999;23(6):553-9.
3. Patiño JF, Echeverri S. Metabolismo, Nutrición, y Shock. Soporte Nutricional en el Paciente con Cáncer. 4 ed. Bogotá: Ed. Médica Panamericana, 2006. p. 1-30. 